Review Article

\title{
A REVIEW ON RECENT ADVANCEMENT IN PULSATILE DRUG DELIVERY SYSTEMS
}

\author{
GAURAV THAKUR ${ }^{1}$, SHAHID UD DIN WANI ${ }^{1 *}$, SURYA PRAKASH GAUTAM ${ }^{1}$ \\ ${ }^{1 *}$ Department of Pharmaceutics, CT Institute of Pharmaceutical Sciences, Jalandhar, India 144020 \\ Email: shahidpharma2013@gmail.com
}

Received: 08 Nov 2020, Revised and Accepted: 10 Jan 2021

\section{ABSTRACT}

Delivery systems with a pulsatile-release method are particularly involved in designing medicines for which traditional managed drug-release systems with the continuous release are not suitable. This medication also has a high first-pass impact or special conditions for chrono-pharmacology. These medications also have a high first-pass or unique chronopharmacological effect. The pulsatile release profile is characterised by a duration of no release (lag time) followed by a fast and full release of the drug. Pulsatile drug delivery systems may be classified into site-specific systems in which the drug is released inside the gastrointestinal system (e. g. colon) or time-controlled devices wherein the drug is released after a well-defined time period. Siteregulated release is typically controlled by environmental factors, such as $\mathrm{pH}$ or enzymes found in the intestinal tract, whereas drug release from timecontrolled processes is controlled mainly by the delivery system and, preferably, not by the environment. This review covers various single-and multiple-unit oral pulsatile drug-delivery systems with an emphasis on time-controlled drug-release systems.

Keywords: Circadian, Pulsatile, Drug delivery, Advancement

(C) 2021 The Authors. Published by Innovare Academic Sciences Pvt Ltd. This is an open access article under the CC BY license (https://creativecommons.org/licenses/by/4.0/) DOI: https://dx.doi.org/10.22159/ijcpr.2021v13i2.41543. Journal homepage: https://innovareacademics.in/journals/index.php/ijcpr

\section{INTRODUCTION}

The circadian behaviour of the disease helps the medicine to release in pulsatile form. Pulsatile forms of drug delivery systems are achieving a lot of interest as they deliver the medicine at a particular time to the actual sight in the right quantity, ultimately offering spatial extent and increasing drug user compliance. Pulsatile form of drug delivery system is defined as the fast and pulsative release of certain amount of active pharmaceutical ingredients moleculae immediately, within a short time frame, and later a pre-determined off-release period. Thus, these systems are designed in such way that based on the body circadian cycle. Principle reasons for the use of pulsatile release of mechanism of action for drugs where a constant drug release, i.e. a zero-order release, is not necessary. To understand the circadian rhythm of the disease, first we need to understand the chronopharmacotherapy or chronotherapeutics. This term 'chrono' in essence to the observations that each and every anabolic and catabolic action go through the rhythmic alteration in time. Many hormonal, metabolic and other function of the body varies considerably in a day. These variations in body system reason alteration in diseased state and in the concentration of drug plasma drug in blood. Circadian rhythm is based on the daily routine which is also include sleep activity, and it is affected by modern gene structure of human and at the end it alters the body's function day and night. The reliance on bodily function in the circadian rhythm in certain disease is well known. Variety of hormone in large number released by brain during morning while different kind of hormones has been released sleeping at night. Blood pressure and heart rate of body are elevated between 6.00 am to 12.00 noon due to circadian rhythm of hormone release. The word "Chronotherapeutics" made up of 2 words, that is 'chronobiology' and 'pharmaceutics'. Chronobiology refers to biology branch which is concerned with the periodicity occurring in living creature. Many diseases follow circadian rhythm for example, hypertension, arthritis, peptic ulcer, asthma, neurological disorder, cancer, diabetes, hypercholesterolemia etc. Some of the above diseases are worse during the day for example, osteoarthritis while some of them are worse in evening and nights during sleep for example cough [1-3]. Current review covers various single and multiple-unit oral pulsatile drug-delivery systems with an emphasis on time-controlled drug-release systems and the recent advancement in pulsatile drug delivery systems

\section{Biological rhythm}

There are mainly three type of biological rhythm (period of oscillation, Dian=time)

\section{Infradian rhythm}

Oscillation which takes more than $28 \mathrm{~h}$ to complete is known as Infradian rhythm, for example-monthly menstruation.

\section{Ultradian rhythm}

Shorter cycle oscillations are named as an ultradian rhythm that is less than $20 \mathrm{~h}$. In physiological processes, Ultradian rhythms were detected, like circulation, cellular cycles, periods of hormone release and sleep, respiration, as well as in behavioural functions, sometimes tied to patterns of feeding.

\section{Circadian rhythm}

Circa stands for circle and dian for time. Circadian rhythms are selfsustaining, occurring oscillations with a frequency of around $24 \mathrm{~h}$. Such rhythms allow organisms to predict and plan for specific and periodic changes in the environment as shown in fig. $1[4,5]$.

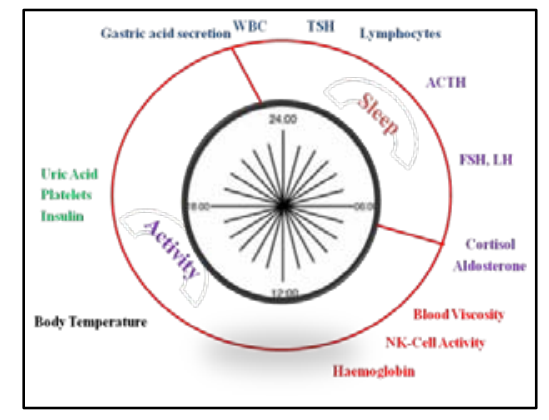

Fig. 1: Cycle of circadian Rhythm [4]

\section{Classification of pulsatile system}

It is mainly in two forms, named as a single unit system and a multiple unit system as shown in table 1.

Single unit system is developed by the use of erodible or breakable coating on core material; it is either in capsule form or in osmotic based type formulation.

Multiple unit system generates pulsatile release by use of different permeability of membrane for coating of beads/core material [6-11]. 
Table 1: Types of pulsatile drug delivery system $[9,10]$

\begin{tabular}{ll}
\hline Single unit system & Capsule based system \\
& Capsule based osmosis system \\
& Erodible or soluble barrier coating \\
& Pulsatile system with rupturable coating membrane \\
Multiple-unit system & Pulsatile system with a rupturable coating \\
& Osmotic based rupturable coating system \\
& Pulsatile Delivery by Change in Membrane Permeability \\
\hline
\end{tabular}

Table 2: Types of pulsatile drug delivery system

\begin{tabular}{|c|c|c|}
\hline Time controlled system & \multicolumn{2}{|c|}{$\begin{array}{l}\text { Pulsatile Delivery by Rupture of Membrane }[11,13] \\
\text { Capsule Shaped Pulsatile Drug Delivery System }[11,14]\end{array}$} \\
\hline Internally Stimuli Induced System & Temperature-induced pulsatile release & $\begin{array}{l}\text { Thermo responsive hydro gel systems }[12,13,18] \\
\text { Thermo responsive polymeric micelle systems }[14,17,19]\end{array}$ \\
\hline & 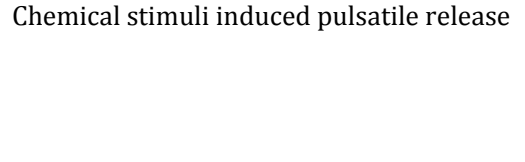 & $\begin{array}{l}\text { Glucose-responsive insulin release devices [15] } \\
\text { PH sensitive drug delivery system [15] } \\
\text { Inflammation-induced pulsatile release [16] } \\
\text { Drug release from intelligent gels responding to antibody [16] } \\
\text { Concentration [16] }\end{array}$ \\
\hline Externally Regulated System & $\begin{array}{l}\text { Magnetic induces release [21] } \\
\text { Ultrasound induces release [21] } \\
\text { Light induces release [21] } \\
\text { Electric field induces release [21] }\end{array}$ & \\
\hline Multiparticulate System & $\begin{array}{l}\text { PRODAS Technology (Programmable Oral D } \\
\text { SODAS Technology (Spheroidal Oral Drug A } \\
\text { CODAS Technology (Chronotherapeutic Ora } \\
\text { DIFFUCAPS Technology [23] } \\
\text { OROS Technology (Osmotic-controlled Rele }\end{array}$ & $\begin{array}{l}\text { rug Absorption System) [22] } \\
\text { sorption System) [22] } \\
\text { Drug Absorption System) [21] } \\
\text { se Oral delivery System) }[9,23]\end{array}$ \\
\hline
\end{tabular}

\section{Types of pulsatile drug delivery system}

As shown in table 2 various types of pulsatile drug delivery systems are as follows

\section{Time controlled system}

\section{a) Pulsatile delivery by solubilisation or erosion of layer}

In this type of delivery system the active drug ingredient release at the site of action where outer polymer layer start dissolving itself due to polymer solubilising property at that area of GIT. Release rate of active pharmaceutical ingredient is controlled by the thickness of coating layer [11-13, 21, 23].

\section{b) Pulsatile delivery by rupture of membrane}

Rupturing of the membrane is achieved by the use of such type polymer which is insoluble in water but water permeable, and the use of the effervescent or swelling agents. Water insoluble coating layer affect the lag time and lag time may alter by the thickness of outer layer [21,23].

\section{c) Capsule shaped pulsatile drug delivery system}

In this type of pulsatile formulation, it contains an insoluble capsule. Plug is fitted within the capsule which creates two chambers in capsule body one is immediate release and other is pulsatile release chamber. The length of the soluble plug inside the capsule control the lag time of drug release $[9,13,14,16,23]$.

\section{d) Pulsatile system based on osmosis}

In this, capsule is coated with semi permeable polymer and it contain insoluble plug which divided the capsule into parts. In capsule, one part contains active pharmaceutical ingredient and the other part contain osmotic agent. When drug is administered the GIT, fluid enter to the capsule through semi permeable side and osmogen create osmotic pressure which move the insoluble plug thus active drug release has achieved $[16,17,19,22]$.

\section{Internally stimuli induced system}

\section{a) Temperature-induced pulsatile release}

Thermal sensitive polymers or hydro gels are used to make these types of pulsatile release formulation. Temperature is mostly used trigging signal for the release of the drug in the body. Body temperature is elevated by the pathogens or pyrogens which lead to alter the size of the hydro gels or polymers and this is followed by release of drug from reservoir [14, 17, 19, 22].

\section{b) Chemical stimuli induced pulsatile release}

In the chemical induced pulsatile system, such kind of polymers are used to develop formulation which alter their size or start solubilising itself when they meet the favourable criteria. For example, glucose responsive polymer, which contain insulin as core material. When glucose level increases in the body then glucose responsive polymer show response and drug released. Similarly, other polymers like $\mathrm{pH}$ sensitive, inflammatory responsive and other enzyme sensitive polymers are used to develop formulation [16, 18, 19, 24].

\section{c) Externally regulated system}

In this, the active pharmaceutical ingredient is contained in device and that device is implanted in the human body. Thus, that drug remains in device unless external signal is not given $[23,24]$.

\section{Magnetic induces release}

It contain magnetic beads along with copolymer matrix which is loaded with particular drug and are implanted in body. When the beads implanted area will exposure to the magnetic field then beads start oscillating and drug will release through the device $[18,19,23]$.

\section{Ultrasound induces release}

Ultrasounds are used to improve the permeation of some drugs in the body. Drugs are loaded in biodegradable matrix and to increase the degradation rate of the matrix to release drug at fast rate ultrasounds are used [18, 23, 24].

\section{Light induces release}

In this type of formulation drug is mixed with such kind of material which absorb light of particular wavelength and that absorbed light helps to regulate release of drug through matrix. For example, Nano shells that absorbed light of near infra red light and generate heat through absorbed light of particular wavelength which leads to collapsing of hydro gels that enhance the release rate of drug through matrix [24]. 


\section{Electric field induces release}

These formulations contain polyelectrolyte or polymer which have number of ions in their backbone. Number of devices are used to perform chronotherapy, thus electric or ph sensitive polymer are used to formulate such kind of device because they alter their structure when they are exposed to external electric field and drug release achieved $[15,19,24]$.

\section{Multiparticulate system}

It is capsular shaped drug formulation containing three parts that core material, coating material and binder or super-disintegrant. The goal of the multiparticulate dosage form design is to create a stable formulation that has all the advantages of formulating a single unit $[19,21,24]$.

\section{CODAS technology (Chronotherapeutic oral drug absorption} system)

In this type of multiarticulate formulation, it contains drug beads coated with two polymers. Some beads are coated with water soluble polymer which released drug immediately and other are coated with water insoluble which show circadian release of drug

Example $=$ Verelan PM XL capsule/Active Pharmaceutical ingredientVerapamil $\mathrm{HCl}$ [24].

\section{SODAS technology (Spheroidal oral drug absorption system)}

These types of formulation comes under customised dosage form for particular patients' accordance of their need. Here few beads are coated with one kind of polymer and other beads are coated with different kind of polymer to achieve pulsative release of drug [24].

\section{PRODAS technology (Programmable oral drug absorption system)}

It contain number of minitablets which are compressed together with active ingredient to form single dose unit. It may fill in capsule and control the rate release of drug [24].

\section{DIFFUCAPS technology}

It release drug in body in circadian manner. It contains core material inert which contain drug in its surrounding. Release rate can control by the thickness of coating material. Example= Innopran XL Tablets Verapamil $\mathrm{HCl}$ [24].

OROS technology (Osmotic-controlled release oral delivery system)

It is similar to the above formulation described in time-controlled system. It contains capsule body which contain plug that create two chambers in capsule. One compartment is filled by osmotic agent and other is filled by drug. Capsule is coated with semipermiable membrane. Osmotic pressure is crested by osmogen and plug moved with to the side of pressure, this led to drug release through the second compartment which contain drug. Example= Alpress LP (prazosin), Covera-HS (Verapamil), Procardia XL [(nifedipine) [25, 26].

Mechanism of action drug release from Pulsatile drug delivery system

The active pharmaceutical ingredients release from pulsatile drug delivery system followed.

\section{Diffusion}

It is the process of movement of material from high concentration to low concentration. It does not require any energy for movement $[27,28]$.

\section{Osmosis}

It is the process of movement of drug particle from/material through semi-permeable membrane from low concentration to high concentration. In this process, movement require external energy which is created by osmogenes $[25,28]$.

\section{Erosion}

In this process the coating membrane start eroding itself with respect to time $[26,28]$.

Also some of the advantages and disadvantages of PDDS are shown in table 3 and 4 below.

Table 3: Advantages of pulsatile drug delivery system [33, 34]

\begin{tabular}{ll}
\hline S. No. & Advantages of pulsatile drug delivery system \\
\hline 1 & Due to Its ability to release immediately at starting increase its absorption and bioavailability at the targeted site. \\
2 & It limits the risk of mucosal irritation. \\
3 & It decreases the loss drug which occurs due to first pass metabolism. \\
4 & Less number of doses intakes without reducing its therapeutic effect as compare to conventional dosage form. \\
5 & There is no effect of food in pulsatile drug delivery system, also GIT ph and fluid does not affect the dosage form because of use of such \\
6 & kind of polymers \\
7 & No risk of dose dumping. \\
8 & Drug interaction is decreased with the use of CYP450 isoenzymes. \\
9 & Patient compliance increases as compare to conventional dosage form. \\
10 & Due to novel drug delivery system undesirable side effects of drugs are avoided. \\
11 & Flexibility in the design of pulsatile formulation.
\end{tabular}

Table 4: Disadvantages of pulsatile drug delivery system

\begin{tabular}{ll}
\hline S. No. & Disadvantages of pulsatile drug delivery system \\
\hline 1. & Drug loading capacity is low. \\
2. & Production of pulsatile drug delivery system is expensive. \\
3. & Lack of manufacturing reproducibility and efficacy. \\
4. & Unpredictable in IVIVC. \\
5. & Advance technology required for production. \\
6. & Larger number of process variable. \\
7. & Trained or skilled person required to perform activities. \\
\hline
\end{tabular}

\section{Disease that required pulsatile drug delivery system}

Body biological process and functions are organized in the time of $24 \mathrm{~h}$ to conduct specific activity in particular time. Numbers of diseases are following the biological rhythm (table 5) $[35,36]$.

\section{Recent advancement in pulsatile drug delivery system}

At present, technology developing rate is high which is helpful for performing the experiments in large number with easy way and in less time. Thus, numbers of experiments were performed and 
numbers of formulation are developed with high efficacy, bioavailability, stability and low risks [35-38, 42].
Some formulation to describe the advancement in pulsatile drug delivery system

Table 5: Diseases that are diagnosed by pulsatile drug delivery system $[35,36]$

\begin{tabular}{llll}
\hline Time & Disease & Chronological behaviour & Used drug \\
\hline $6 \mathrm{pm}, 12 \mathrm{pm}$ & Peptic ulcer & Acid secretion is high in the afternoon and at the night & $\mathrm{H}_{2}$ blocker \\
$12 \mathrm{am} 6 \mathrm{pm}$ & Asthama & During night and early morning & $\mathrm{B}_{2}$ agonist, antihistamine \\
$12 \mathrm{pm}$ & Arthritis & Pain increase at night & NSAIDs's, Glucocorticoids \\
--- & Diabetes mellitus & Increase in blood after meal & HMG CoA reductase inhibitors \\
$8 \mathrm{pm} 4 \mathrm{am}$ & Hypercholesterolemia & Higher during at night as compared to day & Nitro-glycerine, Calcium-channel \\
$6 \mathrm{am}$ & Cardiovascular & Blood pressure reduce during the sleep cycle and start & blocker, ACE Inhibitors \\
& Disease & increasing at early morning & \\
\hline
\end{tabular}

\section{ACCU-BREAK technology}

In this technology, formulation splits itself to small tablets of exact dosage form, thus dose adjustment becomes simple. In ACCU-T-CR tri-layer tablets, tablets contain control release medication and immediate release ingredients $[35,36,38]$.

\section{T M D S technology}

The time multiple action system provided control release rate of multiple ingredients within a single dose [40].

\section{GEOLOCK technology}

This technology contains press-coated tablet in which the active drug stays surrounded by an additional hydrophobic wax layer [40].

\section{DUREDAS technology (Dual release drug absorption system)}

Here bilayer tablets were manufactured. One layer released immediately and other layer release after some time which is predetermined $[39,40]$.

\section{$\mathrm{KV} / \mathbf{2 4}$}

In this, one or more drugs are remaining encapsulated to release drug in predetermine manner. Neutral core which is coated previously is again coated with drug to achieve drug release profile once a day $[38,40]$.

\section{INNOHERB}

It contains pallets coated with polymer and kept in capsule shell. It contains herbal compound [40, 41].

\section{IPDAS technology (Intestinal protective drug absorption system)}

It involve high density compressed form of drug with control release. Normally drug release immediately in GIT but to create control release of drug, bead matrix or semi permeable membrane are used. It comes under multiparticulate system $[39,40]$.

\section{ORBEXA technology}

It comes under multiparticulate in which high drug loaded and product is subject to granulation. After performing further process beads are created and coated with functional polymer [40, 41].

\section{CONCLUSION}

Reduction in drug intake is usually achieved by the discovery of the sustained/controlled drug delivery system and it gains too much attention due to its beneficence. This type of formulation release active drug to the particular site of action at right time, but it does not release active drug according to circadian manner. Due to advance technology and availability of all necessary requirements pharmaceutical field also grow at fast rate and develop such kind of formulation which release in particular manner by following the circadian behaviour of the body. Controlled/Sustained release drug delivery system are much way better than conventional dosages forms and Pulsatile form of drug delivery system have more advantages over sustained release formulations thus by comparing it with conventional dosages form will create great difference related to their advantages and disadvantages.

\section{Future scope}

As in some disease conditions, the prospect of chronotherapy and pu lsatile delivery of drugs seems to be very optimistic in future. Pulsatile drug delivery strategies acquire time-controlled and sitespecific dosage of single or multiple devices. Pulsatile flow in formulation is achieved by use of different kind of polymers and thickness of coating layer also control the rate release of active pharmaceutical ingredient.

\section{ACKNOWLEDGEMENT}

Authors thank the Principal, CTIPS, CT Group of Institutions, Jalandhar and the management for their continuous support and encouragement.

\section{FUNDING}

Nil

\section{AUTHORS CONTRIBUTIONS}

All the authors have contributed equally.

\section{CONFLICT OF INTERESTS}

The Authors declare no conflict of interest, financial or otherwise.

\section{REFERENCES}

1. Gandhi BR, Mundada AS, Gandhi PP. Chronopharmaceutics: as a clinically relevant drug delivery system. Drug Delivery 2011;18:1-18.

2. Amit K, Sonam R. Pulsatile drug delivery system: method and technology review. Int J Drug Dev Res 2012;4:95-107.

3. Aschoff J, Gerecke V, Wever R. Desynchronisation of human circadian rhythms. Japan J Physiol 1967;17:450-7.

4. James A. Physiological functions showing circadian rhythm: Circadian Rhytham; 2018. p. 1-4.

5. Brandenberger G, Charloux A, Gronfier C, Otzenberger H. Ultradian rhythms in hydromineral hormones. Horm Res 1998;49:131-5.

6. Crison J, Siersna PR, Taylor MD, Amidon GL. Control release bioact mater. 1995;22:278.

7. Soutar S, Stevens HNE, Mahony BO. Proc Int Symp Controlled Release Bioact Mater. Bioact Mater 2001;28:790.

8. Shweta A, Ali J, Ahuja A, Sanjula B, Javed Q. Pulsatile drug delivery systems: an approach for controlled drug delivery. Indian J Pharm Sci 2006;68:295-300.

9. Patel VR, Patel PV. P pulsatile drug delivery system. Int J Pharm Sci Res 2015;5:3676-88.

10. Hebden JM, Wilson CG, Spiller RC, GilChrist PJ, BlackShaw PE, Frier $\mathrm{M}$, et al. Regional differences in quinine absorption from the undisturbed human colon assessed using a timed release delivery system. Pharm Res 1999;16:1087-92.

11. Burns JS, Stevens HNE, McEwen J, Pritchard G, Brewer FM, Clarke A, Johnsons ES, et al. Development of efficient acid cleavable multifunctional prodrugs derived from dendritic polyglycerol with a poly(ethylene glycol) shell. J Controlled Release 1996;38:151.

12. Bussemer T, Dashevsky A, Bodmeier R. A pulsatile drug delivery system based on rupturable coated hard gelatin capsules. J Controlled Release 2003;93:331. 
13. Mohamad A, Dashevsky A. pH-independent pulsatile drug delivery system based on hard gelatin capsules and coated with aqueous dispersion Aquacoat ECD. Eur J Pharm Biopharm 2006;64:173-9.

14. Roy P, Shahiwala A. Multiparticulate formulation approach to pulsatile drug delivery: current perspectives. J Controlled Release 2009;134:74-80.

15. Rompicharla B, Prabha KS, Tabasum Md. A comprehensive review of pulsatile drug delivery system. Int Res J Pharm 2012;3:106-8.

16. Amit K, Sonam R. Pulsatile drug delivery system: method and technology review. Int J Drug Dev Res 2012;4:95-107.

17. Rasve G, Borade G, Deshmukh S, Tagalpallewar A. Pulsatile drug delivery system: current scenario. Int J Pharma Bio Sci 2011;2:332-43.

18. Suthar M, Patel U, Brahm Bhatt T, Patel H. Pulsatile drug delivery: a review. Int J Pharm Res Bio Sci 2007;1:3-12.

19. Tajane SR, Kholwal BB, Suryawanshi SS, Tarkase KN. Current trends in pulsatile drug delivery system. Int J Pharm Sci Res 2012;3:358-63.

20. Singh DK, Poddar AS, Nigade SU, Poddar SS. Pulsatile drug delivery system: an overview. Int J Curr Pharm Rev Res 2011;2:55-80z.

21. D'Souza, Sutar KP, Sutar PS, Nadgouda S. The use of chronotherapeutics in design of pulsatile delivery system-a review. J Pharm Sci Innovation 2012;2:50-5.

22. Vinupama S, Shwetha S, Kamath K, Keerthi TS. Pulsatile drug delivery system: a review. Int Bull Drug Res 2012;1:19-31.

23. Gajbhiye ND, Vilasrao JK, Kisan RJ, Anand UK. Pulsatile drug delivery system. J Pharm Res 2010;2:120-3.

24. Singh Anamika, Dubey Harikesh, Shukla Indu, Singh Dharmchand P. Pulsatile drug delivery system: an approach of medication according to circadian rhythm. J Appl Pharm Sci 2012;2:166-76.

25. Singh A, Dubey H, Shukla I, Singh DP. Pulsatile drug delivery system: an approach of medication according to circulation rhythm. J Appl Pharm Sci 2012;2:166-76.

26. Rajput M, Sharma R, Kumar S, Jamil F, Sissodia N. Pulsatile drug delivery system: a review. Int J Res Pharm Biomed Sci 2012;3:118-22.

27. Kumar GA, Bhat A, Lakshmi AP, Reddy K. An overview of stimuli-induced pulsatile drug delivery system. Int J Pharm Tech Res 2010;2:3658-2375.
28. Kanchan Mandal M, Joshi AL, Raval A, Patel YK. Pulsatile drug delivery-a better chronothepy system: a review. World J Pharm Res 2018;7:690-705.

29. Harikeshn D. Pulsatile drug delivery system: an approach of medication according to circadian rhythm. J Appl Pharm Sci 2018;2:166-76.

30. Suresh R. Design, development and evaluation of press coated tablets of an eprosartan mesylate. Bull Pharm Med Sci 2014;2:2347-55.

31. Chourasia MK, Jain SK. Pharmaceutical approaches to colon targeted drug delivery systems. J Pharm Pharm Sci 2003;6:33-66.

32. Kuotsu K, Nikhil B. Drug delivery system based on chronobiology-a review. J Controlled Release 2010;147:31425.

33. Vipul PP, Soniwala Moinuddin M. Pulsatile drug delivery system for treatment of various inflammatory disorders-a review. Int J Drug Dev Res 2012;4:67-87.

34. Modasiya Moin K, Vishnu PM. Pulsatile drug delivery system for colon-a review. Int J Res Pharm Biomed Sci 2011;2:934-41.

35. Pandit V, Kumar A, Ashawat MS, Verma CP, Kumar P. Recent advancement and technological aspects of pulsatile drug delivery system-a laconic review. Curr Drug Targets 2017;18:1191-203.

36. Patwekar SL, Baramade MK. Controlled release approach to novel multiparticulate drug delivery system. Int J Pharm Pharm Sci 2012;4:756-63.

37. Ravula AN, Goud BA. Recent advances in oral pulsatile drug delivery. J Adv Pharm Sci 2011;1:57-62.

38. Rosenmayr Templeton L. The elan of delivery technology development. Int Association for Pharmaceutical Technology Newsletter; 2011. p. 2.

39. Dey NS, Majumdar S, Rao MEB. Multiparticulate drug delivery systems for controlled release. Trop J Pharm Res 2008;7:1067-75.

40. Shidhaye S, Dhone A, Budhkar T, Surve C. Technologies in pulsatile drug delivery system. Int J Adv Pharm Biol Chem 2012;1:438-45.

41. Kalantzi LE, Karavas E, Koutris EX, Bikiaris DN. Recent advances in oral pulsatile drug delivery. Recent Pat Drug Delivery Formul 2009;3:49-63.

42. Wani SUD, Gangadharappa HV, Ashish PN. Formulation, development and characterization of drug delivery systems based telmisartan encapsulated in silk fibroin nanosphere's. Int J Appl Pharm 2019;11:247-54. 